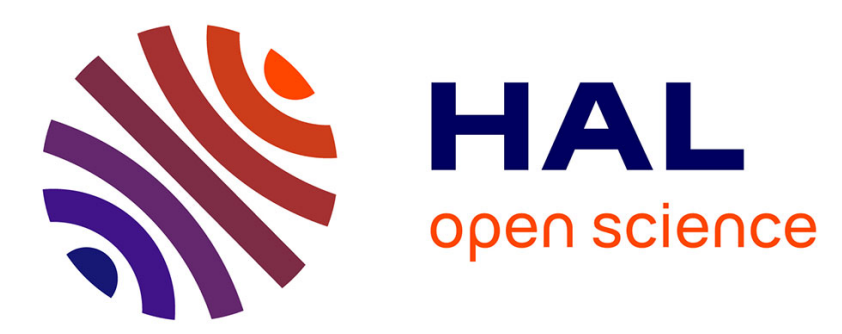

\title{
Fairness, Regulation of Technology and Enhanced Human: A Comparative Analysis of the Pistorius Case and the Cybathlon
}

\author{
Rémi Richard, Damien Issanchou, Sylvain Ferez
}

\section{- To cite this version:}

Rémi Richard, Damien Issanchou, Sylvain Ferez. Fairness, Regulation of Technology and Enhanced Human: A Comparative Analysis of the Pistorius Case and the Cybathlon. Sport, Ethics and Philosophy, 2020, pp.1-15. 10.1080/17511321.2020.1818278 . hal-02938971

\section{HAL Id: hal-02938971 \\ https://hal.umontpellier.fr/hal-02938971}

Submitted on 15 Sep 2020

HAL is a multi-disciplinary open access archive for the deposit and dissemination of scientific research documents, whether they are published or not. The documents may come from teaching and research institutions in France or abroad, or from public or private research centers.
L'archive ouverte pluridisciplinaire HAL, est destinée au dépôt et à la diffusion de documents scientifiques de niveau recherche, publiés ou non, émanant des établissements d'enseignement et de recherche français ou étrangers, des laboratoires publics ou privés. 


\title{
Sport, Ethics and Philosophy
}

\section{Fairness, Regulation of Technology and Enhanced Human: A Comparative Analysis of the Pistorius Case and the Cybathlon}

\author{
Rémi Richard, Damien Issanchou \& Sylvain Ferez
}

To cite this article: Rémi Richard, Damien Issanchou \& Sylvain Ferez (2020): Fairness, Regulation of Technology and Enhanced Human: A Comparative Analysis of the Pistorius Case and the Cybathlon, Sport, Ethics and Philosophy, DOI: 10.1080/17511321.2020.1818278

To link to this article: https://doi.org/10.1080/17511321.2020.1818278 


\title{
Fairness, Regulation of Technology and Enhanced Human: A Comparative Analysis of the Pistorius Case and the Cybathlon
}

\author{
Rémi Richard (D) , Damien Issanchou ${ }^{\mathrm{b}}$ and Sylvain Ferez ${ }^{\mathrm{c}}$ \\ aLaboratoire Santésih (EA 4614), University of Montpellier, Montpellier, France; 'Laboratoire L-VIS (EA 7428), \\ University Claude Bernard Lyon 1, Lyon, France; 'Laboratoire Santésih (EA 4614), University of Montpellier, \\ Montpellier, France
}

\begin{abstract}
Ensuring fairness is a capital issue in any sporting competition. However, fairness is a complex concept. We seek here to offer an analysis of the construction and upholding of fairness within competitions in which disabled people make use of assistive technology in order to perform. In this view, we look into two cases which question, in different manners, the issues surrounding the use of technology and sporting fairness: the cases of Oscar Pistorius and of the Cybathlon. On the one hand, in the Pistorius case, the sporting institution seeks to regulate the use of technology through a scientific measure of the advantage it may grant the athlete. The difficulty of determining this advantage, and of classifying Pistorius' performance, promoted the production of an enhanced human imagery. On the other hand, with the Cybathlon, a competition including highly technologised athletes, the promoters try on the contrary to highlight the advantages that technology can procure. The aim in that case will be for the organisers to set in place a system of rules that mirror those of sporting fairness, in spite of the central position given to technological performance. The purpose of this essay will be to understand how this sporting fairness is constructed and negotiated within two specific cases portraying the sporting practices of disabled people.
\end{abstract}

\section{KEYWORDS}

Fairness; technology; disability; Oscar Pistorius; Cybathlon

\section{Introduction}

Fairness constitutes an essential sporting value (Brown 2015). However, it is a complex concept which is difficult to define. The natural character of a sporting performance is often highlighted by sporting authorities (Carstairs 2003; Hilvoorde and Landeweerd 2008) as being an empirical foundation of fairness in sports. Nevertheless, determining the natural or unnatural character of a sporting performance seems to lead to a theoretic dead-end (Loland 2018). Indeed, it would appear quite impossible to trace a direct line separating the techniques, substances, and methods that are either natural or artificial. In the words of Carr, 'the various methods and substances athletes use to enhance performance are not pre-labelled as artificial or natural; this is a distinction we elect to impose 

upon them' $(2008,194)$. This separation line, once it has been traced, reveals above all a social interpretation, a natural ideal that evolves over time and to the rhythm of cultural changes (Loland and Hoppeler 2012). These categories are socially produced in order to ensure a form of sporting equity and are subsequently naturalized. The argument of a natural performance is proof of the essentialization of normalized social practices. For Carr, sporting fairness implies, above all, 'fidelity to social practice' $(2008,195)$. There is inequity when the social rules that have been fixed for the practice are not respected. This being said, concerning doping, whether technological or not, it is the ideal of a natural performance, non-'enhanced', that serves as a basis for the social construction of the practice's rules (Loland 2018).

Sporting categories are a good example of rules that were established socially in order to ensure sporting fairness. The production of sporting categories can be based on social norms that are external to the strict field of sports, such as gender (Teezle 2006) or disability. The goal will thus be for the sporting authorities to measure the conformity of the athletes to these categories (Gleaves and Lehrbach 2016). Other categories, such as weight for instance, can be employed in order to limit inequities linked to the genetic lottery (Loland 2018). For Shaskin and Williams 'one of the most obvious elements of fairness is equitable treatment' $(1990,61)$. Equity is the manner in which fairness is going to appear or be demonstrated. The purpose of sport categories is to establish equitable and therefore fair sporting competition.

Sporting fairness is also ensured by a process of classification of the technology, substances and methods employed in order to prepare the sporting performance, or to carry it out. Those that provide the athlete with too much of an advantage are considered unfair and illicit. Doping then becomes a situation in which the athlete obtains an advantage that is judged as being too strong from the use of a certain substance, practice or technology. The question is no longer to determine the 'natural' or not character of a potentially doping practice, but to scientifically measure the advantage that it grants. A technology which would induce too much advantage for an athlete risks being considered unfair, and therefore being banned. This is the case, for instance, of doublestrung rackets in tennis or full-body polyurethane swimsuits, which are considered as a form of techno-doping by the international tennis and swimming federations. More recently, the same question arose for Nike's Vaporfly running shoes (Dyer 2020) used by athlete Eliud Kipchoge, first athlete to complete a marathon in less than two hours. The standardisation of equipment thus becomes a means to ensure fairness within sporting competitions (Carr 2008; Ryall 2013).

In the situation where assistive technology is used by disabled people, the question of fairness is even more difficult. Indeed, the use of advanced assistive technology in the field of sports raises the issue of the separation between assistance and enhancement (Wolbring 2008). Does this technology enable athletes to outperform 'human' abilities? To what extent must it be considered as techno-doping? Wolbring also shows that the rapid evolution of assistive technology, in association with the transhumanist culture, led people to 'perceive the improvement of human body abilities beyond species-typical boundaries not only as desirable but as essential' $(2012,255)$. This is particularly true in the field of sports where overcoming boundaries (and the performance of others) is a fundamental value (Cléret and McNamee 2012). Athletes using advanced assistive technologies support the figure of the sports cyborg ${ }^{1}$ as a hybrid being, made of flesh 
and technology (Howe 2011; Richard and Andrieu 2019). These athletes question the nontherapeutic (Wolbring 2012) use of assistive technology and the unfair advantage it procures. They raise the issue of the principle of fairness, since the technology employed questions both the natural character of the performance, but also and foremost, the legitimacy of the sporting performance in view of the unfair technological advantage.

The aim of this essay will be to understand how this sporting fairness is constructed and negotiated within two practical cases portraying the sporting practices of disabled people; namely the controversial participation of Pistorius to non-disabled sport, and the Cybathlon, a competition for disabled athletes who use advanced assistive technology. In order to do this, we will analyse the discourse production and sporting regulations that participate in the construction of the principle of equity in each of these cases. In parallel, we will evidence how this regulation of technology fuels the imagery of an enhanced human.

\section{The Pistorius Case}

Born with non-functional legs, ${ }^{2}$ Oscar Pistorius dedicated his life to competing alongside the elite of 'non-disabled athletes'. This sport participation has been widely discussed within the media since it is viewed as extraordinary: 'At 11.15, Oscar Pistorius will present himself on the track of the Olympic stadium, thus becoming the first disabled athlete to compete in the Olympics alongside non-disabled ones' (Le Parisien, 4 August 2012, 16). However, other athletes (designated as disabled) had already, long before Pistorius, ${ }^{3}$ taken part in non-disabled competitions. In the case of Oscar Pistorius, this participation did not seem to be quite so straightforward (Marcellini et al. 2012; Norman and Moola 2011) and produced many debates in the media (Corrigan et al. 2010; Smith 2015). Thus, the singular situation of this athlete was 'problematicating' (Bensa and Fassin 2002; Deleuze 1969). Media discourse emphasized how meaningless it was, from a sports point of view, to compare Oscar Pistorius' performance with that of non-technology assisted athletes (Léséleuc and Issanchou 2016). In this way, the French media hype regarding a South-African runner whose performances were below the minimum Olympic qualification time makes sense (Bourdieu 1994; Marchetti 2002; Papa 1998), since this case was challenging sport classes and organisation (Issanchou, Ferez, and de Léséleuc 2018; Swartz and Watermayer 2008).

Specifically, the difficulty to apprehend Pistorius' participation is related to the impossibility of assessing whether he obtained or not unfair advantage over non-technology assisted athletes (Issanchou, Ferez and Léséleuc 2018). On the one hand, between 2008 and 2012, he is clearly faster than other amputees. ${ }^{4}$ Thus, his performances cannot only be attributed to his prosthetics but also to his natural body. On the other hand, his rapid ascent to top-level sports and his stride length suggested that his prosthetic limbs allowed him to achieve such great performances. This stimulated the use of symbolic terms regarding the imaginary of the enhanced human. Indeed, within media discourse, Pistorius was introduced as 'Blade Runner' (Le Monde, 30 June 2007, 16), or 'the UFO Pistorius' (Le Parisien, 4 August 2012, 16). 


\section{A Performance that Defied Classification}

For the first time in his sporting career, on 13 July 2007, Oscar Pistorius participated in the 400-metre during the Rome meeting. The young South-African was not selected for the $A$ race (involving the highest performing athletes). In view of research on sporting information evidencing a focus on sports with larger audiences (Marchetti 2002), on stars (Papa 1998), or on national sportsmen/women (Bourdieu 1994), his participation was the source of a surprisingly strong coverage by the French media. The discourses concerning Pistorius were percolated with much opposition which is proof of the difficulty to qualify him sportively (Corrigan et al. 2010; Smith 2015). These objections were organised around an original opposition between him being 'too good' versus 'not good enough', which brings light to the intermediary level of Oscar Pistorius' performances. Initially, his sporting achievement seemed to separate him from the 'disabled athlete' category. This symbolic separation led Pistorius to a liminal in-between situation (Gardou 1997; Turner 1990), since his performances did not allow him to be recognised as a nondisabled athlete either. This aspect was made stronger in 2008 when Pistorius did not manage to qualify for the Olympics, when he had so easily obtained three gold medals during the Paralympics. On 9 September 2012, L'Equipe (French sports journal) was titled for instance: 'Pistorius between two worlds'.

In this context, what was preventing the sporting performance comparison which is usually so easily deployed? Pistorius' prosthetics were at the centre of the sporting and media attention because of the difficulty to precisely perceive the role played by this equipment in his performance (Jones and Wilson 2009). Thus, the International Association of Athletics Federation (IAAF) considered that it was necessary to verify whether or not the prosthetics' efficiency was equivalent to that of a non-disabled athlete's legs. That is why the IAAF mandated Professor Brüggemann to conduct a biomechanical study of Pistorius' prosthetics. In this way, the comparison between a prosthetic's efficiency and that of an athlete's leg was instituted as a criterion for judging the equity of a competition opposing Pistorius and non-disabled athletes. This evaluation and regulation of athletic performance ignores the subjective experience of Pistorius. Thus, the process by which Pistorius became a sporting cyborg (Sparkes, Brighton, and Inckle 2018) is not addressed.

\section{Engaging in Scientific Controversy ${ }^{5}$}

Accused of having adopted rule $144.2 \mathrm{e}^{6}$ against Pistorius specifically, the IAAF officials explained that it would only be able to prevent him from participating in competitions on the condition that a scientific proof could be produced that his prosthetics gave him an unfair advantage over non-disabled runners. ${ }^{7}$ To end the controversy, the IAAF intended to use a scientific comparison of the efficiency of both prosthetics and non-disabled athletes' legs. Resorting to this measure was seen as legitimate within the international press. ${ }^{8}$ As mentioned previously, we can see here how sport governing bodies, but also the international press, compartmentalized Pistorius into human and mechanical parts whilst neglecting his experiences as an athlete (Sparkes, Brighton, and Inckle 2018). On 15 December 2007, the Brüggemann report concluded that Pistorius' prosthetics were more efficient, regarding the variables measured, ${ }^{9}$ than the legs of the non-disabled 
athletes who took part in the study. On 14 January 2008, based on these conclusions, the IAAF considered that Pistorius gained unfair advantage and banned him from taking part in competitions. Disagreeing with the conclusions of Professor Brüggemann, Oscar Pistorius appealed this ban in front of the Court of Arbitration for Sport (CAS). Within the press, appeared a diverging opinion concerning the legitimacy of the ban pronounced by the IAAF. It denounced the scientific invalidity of the tests that were carried out and which 'were incomplete [and] were solely biomechanical' (L'Equipe, 15 January 2008). 'In particular, Pistorius may assert that the study does not take into account his disadvantage when starting up' (Le Figaro, 15 January 2008, 11). Thus, the diverging opinion was based on the idea that the study did not bring the proof of Pistorius' unfair advantage because it did not take into account enough scientific variables.

This scientific controversy continued during the auditions for the trial. Experts were called upon in order to analyse the Brüggemann report. The scientific or 'metrological' debate (Adam and Trabal 2013; Jones and Wilson 2009) mainly concerned one of the conclusions of this study: Pistorius used less metabolic energy than his non-equipped competitors. On 16 May 2008, the CAS referees decided to revoke the ban, based on the fact that the conclusions of the Brüggemann report were insufficient. In this manner, their decision was not motivated by the proof of the absence of advantage for Pistorius over non-disabled athletes, but rather by a lack of elements proving that he was advantaged. Thus, the role played by the prosthetics in Pistorius' performance remained uncertain. In other words, the panel refused to ban Pistorius only because there was no proof of an unfair advantage. That is why, immediately after giving their verdict, the CAS officials emphasized that the IAAF would be able to re-open the Pistorius case as soon as it could find new elements proving his advantage. The report clarified:

The Panel does not exclude the possibility that, with future advances in scientific knowledge, signed and carried out to the satisfaction of both Parties, the IAAF might in the future be in a position to prove that the existing Cheetah Flex-Foot model provides Mr Pistorius with an overall net advantage over other athletes. ${ }^{10}$

\section{Imaginary of the Enhanced Human}

The impossibility to scientifically determine whether Pistorius obtained an unfair advantage with his prosthetics prevented his participation alongside able-bodied athletes from being meaningful. Pistorius was granted access to the Olympics but still there was doubt regarding the comparable nature of a competition between him and non-equipped athletes (Jones and Wilson 2009). This uncertainty stimulated the use of symbolic terms following two themes: uniqueness and human enhancement. Although they were already present in the international press in 2007, those themes appeared with more clarity following Pistorius' qualification for the 2011 Deagu World Championship and for the 2012 London Games. Uniqueness was notably the theme that organised the contents of press articles produced in 2012. For instance, it was written that 'his story as a man with no legs is unique' (Le Monde, 6 August 2012, 3).

As mentioned above, Pistorius was not the first disabled athlete to compete alongside able-bodied athletes. Nevertheless, in 2011 and 2012, he was systematically presented as the first and unique in this case. Once more, his singularity was emphasized using the 'first 
registered case' theme: 'Oscar Pistorius became the first double amputee to run an Olympic race amongst non-disabled athletes, during the first series of the $400 \mathrm{~m}$ in the London Olympic Games." (Ouest France, 5 August 2012). What is more, the symbolic organisation of the media discourse supports the idea, which it actually directly evokes several times, that Pistorius is an intermediary figure between disabled and able-bodied athletes (Corrigan et al. 2010; Magdalinski 2012). For example, L'Equipe titled one of its articles: "Pistorius between two worlds" (9 September 2012, 12). This liminal state (Gardou 1997) was strengthened by his victory, perceived as a crushing one, during the 400 metres at the London Paralympic Games. The press articles notably highlighted that the South-African sprinter did not have any Paralympic competitors on his level: "the South-African, amputated of both legs, demonstrated that he was still alone on his own planet, by dominating the turn of the track in 46"68, far in front of the American Leeper (50'14)." (L'Equipe,

9 September 2012, 12) This in-between character can also be seen as the humanmachine mix. In this way, Pistorius became the 'latest avatar for the duality of man and machine' (Lemonde.fr, 28 August 2011). The title of an article in Le Monde, published one year later, was also evidence of this: 'Oscar Pistorius, the proto-athlete' (6 August 2012, 3). This hybrid image was strengthened by an opposition structuring the discourses concerning Pistorius' performances, between what is produced by the body and what is produced by the equipment. Those elements lead us to recognise that because competitive sports "tend towards, endorse and depend upon the physical transcendence of humanness [it] offers a unique environment where transhumanism can gain social credibility" (Miah 2003).

Furthermore, the idea emerged that Pistorius might overthrow the sporting hierarchy in which it would be ordinary for an athlete presenting a physical impairment to produce an inferior performance compared to a non-disabled one. This projection into the future occurred several times in the corpus analysed, looking to emphasize the need of a reaction from the sport governing bodies. Oscar Pistorius was then regarded as a turning point in sporting history as if his participation would be setting a precedent regarding the use of technical devices. Thus, even if Oscar Pistorius had never won a major able-bodied sporting event, ${ }^{11}$ his situation had stimulated discourse regarding human enhancement. ${ }^{12}$ In this context, it is not surprising that the South-African athlete was constantly cited within the philosophical-journalistic writings of trans- or post-humanistic inspiration which flourished at the beginning of the years 2010.

\section{Overcoming Disability with Technosports: The Cybathlon Showcase}

Whereas in the case of Pistorius, one individual called into question the rules established by the institution 'from the inside', in the case of Cybathlon, it is an 'outside' logic that challenges the sports world. Indeed, this competition was born outside the framework of traditional sporting institutions, on the basis of entirely new modalities for competing. It was organised by the engineers of the Federal Institute of Technology (ETH) of Zurich, upon the initiative of Robert Reiner, Professor of sensory-motor systems. The first edition of the Cybathlon took place on 8 October 2016 at the Swiss Arena Kloten. The event, presented as a 'new kind of championship' (Issanchou, Ferez, and de Léséleuc 2018) included six competitions. The latter were organised as races during which individuals with 
amputations or partial or complete paralysis competed whilst using advanced assistive technology.

The six disciplines comprise races with powered leg prostheses, powered arm prostheses, functional electrical stimulation (FES) driven bikes, powered wheelchairs and powered exoskeletons. The sixth discipline is a racing game with virtual avatars that are controlled by braincomputer interfaces (BCI) (Riener 2016).

From the start, the Cybathlon laid the question of its position in relation to the field of sports. Does this event, which emerged from the field of engineering sciences, take part in a 'sporting tradition' by replaying its fictions of equity or, on the contrary, does it constitute a radical questioning of the 'traditional' (bio)sporting model?

\section{The Sporting Showcasing of the Cybathlon}

For the press, there was no doubt concerning the Cybathlon's filiation with the 'classical' sporting field (Wolbring 2018). In the media, it was considered as the logical evolution of sport; the press thus spoke of 'Games of a new type', or of 'bionic Olympic Games'. ${ }^{13}$ Elsewhere, they were described as 'cyborg Olympic Games'. Some journalists even went so far as to consider this competition as the future of modern sports.

What is more, the organisation of the Cybathlon, and indeed its communication, greatly participated in the production of a link with the classical sporting world, and more particularly with the Paralympic one. It is the role of the Cybathlon Sport Director, Roland Sigrist, to ensure this filiation. Indeed, the latter had a double skillset which made legitimate his position as guarantor of the event's sporting nature. A researcher in engineering sciences (he completed his $\mathrm{PhD}$ 'on the topic of complex motor learning with augmented feedback ${ }^{14,}$ ), Roland Sigrist was also a sports teacher at ETH Zurich. In his discourse, there is no doubt concerning the sporting dimension of the Cybathlon: 'As I like sports and planning, it was clear to me that I would do the job'. His role as head of the sporting and competitive side of the Cybathlon was to 'design the course and the rules'. ${ }^{15}$ Shaping the competition in this way contributed to make the sporting nature of the event more conspicuous. The organisers of the Cybathlon used the main traits that characterised the (Para)Olympic competitions (Reid 2017) and, from a structural point of view, the similarities were numerous. The races were organised in phases with qualifications and finals; scoring and ranking systems were thoroughly elaborated for each discipline; extremely precise regulations were applied to each competition and referees guaranteed the application of those rules. Indeed, it was noted that:

In case of any inconclusive occurrence or situation beyond the referee's decision, rules or regulations, the Competition Director will be the supreme authority (Cybathlon 2016, 5).

From a symbolic point of view, the proximity of the Cybathlon with other big sporting competitions, and more particularly with the Olympics and Paralympics, was also striking. Indeed, the rites of the great sporting competitions were replayed here. The opening and closing of the Cybathlon were punctuated with a tour on the tracks to the accompaniment of music, along with the mascots of the event. As with the Olympics and Paralympics, a medal ceremony greeted the winners, installed on podiums, after each race. This symbolic proximity with the Paralympics was also maintained in the shape of sponsoring by 'experts'. These individuals, qualified as experts, were athletes who were engaged in the Paralympic 
Games of Rio $2016 .{ }^{16}$ The mirroring used by the organisers most certainly aimed to benefit from the public's keen interest in sporting events and from the media coverage that this induced. Nevertheless, in spite of this mirroring, and because of the technological issues at stake, the Cybathlon questioned the standards of the sporting world, as well as those of the Paralympics (Richard and Andrieu 2019; Wolbring 2018).

\section{Making Scientific Progress Visible and Legitimising the Competition of Highly Technologised Athletes}

In the manner in which it unfolded, the Cybathlon appeared to have everything that a classic sporting competition should have. Nevertheless, some fundamental diverging points with the sporting world can be identified, particularly with the Olympics and Paralympics.

To begin, the comparison between the values and objectives displayed by the Cybathlon and those shown by the Olympic and Paralympic Games highlights strong differences. On questions such as empowerment and inclusive societies, the events are in agreement. The IPC explained wanting 'to make for a more inclusive society for people with any impairment through Para sport' and 'creating conditions for athlete empowerment' ${ }^{17}$ For its part, the Cybathlon 'wants to promote the discourse on the inclusion and equality of people with disabilities in everyday life'. However, these preoccupations only appear as secondary and the main missions put on display by the Paralympics and the Cybathlon are radically different. Through the promotion of high level sport for people with disabilities, the IPC defends the Coubertin values of courage, determination and overcoming one's own limits (Martinkovà 2012). The IPC maintains close ties with Olympism (of which it has the recognition) while maintaining its own identity. With the Cybathlon, it is not directly a question of overcoming one's limits, but rather of promoting techno-scientific progress. The event takes place in a different social space, that of techno-sciences and their medical uses. The aim for the organisers is 'to promote the research, development and implementation of assistive technologies for people with disabilities'. Thence, the Cybathlon is above all an occasion for making visible the progress of advanced assistive technology through the participants' performances. Additionally, it is this desire to promote robotics which certainly produces the biggest difference between the (Para)Olympics and the Cybathlon: the value given to the competition of 'highly technologised' bodies, which constitutes the heart of the event. These relations with technology engage each event in very different outlooks.

The sporting display appears, in this instance and above anything else, to constitute a showcase for the promotion of robotics research. Indeed, although numerous structural and symbolic elements would indicate a filiation with an Olympic or Paralympic event, this is not explicitly 'accepted' by the organisers. The Cybathlon seemed to 'surf' on the public's hype for sporting competitions, all the while expressing its distance from the Paralympic movement. This distance relates, in effect, to technological issues. Questioned on the subject, Robert Riener explained that, in the Paralympic Games, 'technology remains in the background and the use of motorised wheelchairs or powered prostheses is not permitted'. ${ }^{18}$ Whereas the (overly) assisted performance was banned from the Olympics and Paralympics (or made invisible by the standardisation of equipment), 
because it was considered as a form of technodoping (Mc Namee 2014), the Cybathlon turned it into the heart of the competition. In this way, the Cybathlon openly claimed to be the only competition whose participants (named 'pilots' for the occasion) use powered prostheses. In so doing, the event contributed to rendering highly technologised sporting bodies legitimate, by playing the game of a cyborg demonstration (see Richard and Andrieu 2019).

Simultaneously, the central place allocated to advanced assistive technology allowed the Cybathlon to differ in a second manner. Indeed, according to the organisers, the technology promoted by the event is firstly aimed at people who are 'severely disabled', and who are often excluded from the Paralympics because they use power-assisted technology to practice sport. In this sense, the Cybathlon was an entirely new situation for these people to compete in: 'in contrast to the Paralympic Games, it allows the use of any kind of technical aids, thus also enabling people with more severe disabilities to participate in a competition' (Riener 2016). Although the Cybathlon organisers are proposing a new competition area for severely disabled people, the very high cost of technology limits participation to the most financially privileged teams. The empowerment of disabled people promoted by the organisers comes up against the economic reality, as evidenced by the virtual absence of teams from developing countries.

Lastly, the final essential difference resides in the very nature of the competitions. Indeed, although the format of the contest was mostly the same as in any other sporting competitions, the actual races were for the most part quite distant from classical sporting activities. Inspired by everyday tasks (sitting down, using laundry pegs, going up stairs), the Cybathlon tasks diverge from the specificity of sporting events, but also from the cyborg imagination (Frias 2016). Indeed, whereas cyborg athlete imagination is based on a figure overcoming human abilities (running speed, jumping height etc.), in the case of the Cybathlon, it is everyday skills that are performed (Richard and Andrieu 2019).

All these elements provide evidence of the complex links that the Cybathlon maintains with the sporting world. Through its showcasing, the organisers produced some proximity with classical sporting events, while simultaneously establishing its distance from the latter through their discourse. In an article of the Journal of NeuroEngineering and Rehabilitation presenting the Cybathlon, Riener (2016) evoked a form of complementarity with the Paralympics: 'Cybathlon can also be considered as a complement to the Olympic or Paralympic Games'. These statements contributed to maintaining the blurred lines surrounding the relations between these events.

All things considered, playing the game of the sporting showcase however imposed a constraint on the Cybathlon: equity on the starting line is an absolute prerequisite for the sporting display. What is more, in this never-seen-before competitive context, the issue of classifying and measuring the 'advantage' had a tendency to resurface.

\section{The Issue of Sporting Fairness and Regulating the Robotised Performance}

It would thus seem that, for the organisers of the Cybathlon, the competition provided above all a 'stage' on which to highlight technological performance. However, this showcase involved submitting to certain requirements. Hence, for the show to be guaranteed, the organisers needed to make sure of the equity of all the participants on the starting line In the Cybathlon, the 'hybrid' nature of the performance made the constraint double. For each competition, there needed first of all to be a kind of equity amongst the pilots: what 
should the 'maximum' capacities of the pilot be? To what extent does the impairment not generate too big of a (dis)advantage? This is a classical conundrum with which the Paralympics are already faced (Pickering Francis 2005). In addition, there must also be technological fairness: on what criteria is the technology accepted, and what type of technological assistance is authorised (Carr 2008; Ryall 2013)? Regarding these two issues, it is legitimate to question the Cybathlon's ideal of equity.

As we found with the example of Pistorius, the criterion used by the Olympic officials in order to guarantee equity was one concerning the origin of the performance: the athlete must not gain any advantage from technology. In the case of the Cybathlon, technology is at the very heart of the production of the performance. In this situation, the question pertains to the 'nature' of the performances that the Cybathlon seeks to showcase and to compare. Are they performances of a disabled body? Or is it the mastery of an enhancement technology at the service of a 'diminished' body? Several elements provide an answer to these questions.

To begin, there is the use of the substantive 'pilot'. This term comes from the Greek pêdon which originally designated the rudder of a ship, the element that guides the machine. By extension, it designates nowadays the person who will drive any transportation device (particularly in motorised sports). The performance of a pilot therefore does not reside so much in a 'physical' performance as it does in a skill for interacting with the tool, a capacity to 'guide' a technology. The use of this term neutralises, in a certain way, the central position of the 'natural' body of the person as a source for the performance, and questions the athlete's physical commitment, much like in eSports (Parry 2019; Hilvoorde and Pot 2016). At least, it shifts the performance from its 'organic' substance in order to locate it within its interaction with an advanced assistive technology. In this manner, Riener explained: 'The competitors are called pilots, as they have to control a device that enhances their mobility'. It could be said that, in this case, the evaluation of a pilot consists, in a certain manner, in measuring their propensity for their body to become one with the technology: 'The goal is not to be the fastest and the strongest among the participants, rather the goal is to be the most skilled pilot who utilizes advanced technologies' (Riener 2016). In this context, inclusion criteria must be established both for the pilots and for the technology.

The inclusion criteria for the pilots are not without similarities to the Paralympic classifications systems (Jones and Howe 2005), since these include both biomedical and functional aspects determining the possibility to take part in the Cybathlon:

In the pilots' inclusion criteria for each discipline, the minimal requested level of the pilots' lesion or amputation is defined. Pilots who have more severe handicaps can be included, although they might have a disadvantage in comparison with the target group. Each case is individually checked by the committee to ensure that the difference, i.e. disadvantage, is not too distinct (Cybathlon Races \& Rules 2016, 1).

On the matter of technology, the Cybathlon rules and regulations do not impose any limits concerning the advantage obtained through it. On the contrary, the aim of the rules is to set up a competitive situation in which the technological advantage is the main stake. On the event's website, there is written: 'The rules of the competition are made in such way that the novel technology will give the pilot an advantage over a pilot that would use a comparable but less advanced or conventional assistive technology'. The 
only restrictions concern forms of technology which would allow a remote control of the device. It is therefore stated in the rules and regulations that:

Communication (wired or wireless) between the device and any third-party stationary site is not allowed, i.e. remote connection to control the device by any person other than the pilot is forbidden, except for emergency stop and data monitoring. (Cybathlon 2016, 2).

Since it is the advantage that an individual can grasp through the use of technology in a situation of competitive sport that is at the heart of the show during the Cybathlon, the rules do not need to ensure any form of technological 'neutrality', but a certain 'authenticity' of the man/machine interaction. As in Formula 1 races, it is the individual's ability to control a technology to achieve the best performance that is at stake in the Cybathlon. It would not be fair that in a car race a third party should intervene in the piloting of the machine thanks to a remote controlled system. The fairness of these competitions therefore relies essentially on the driver's mastery of the technology to get the maximum advantage. In placing technological advantage at the centre of the competition, the Cybathlon takes an opposite approach from the one employed for the Olympics and Paralympics. The 'artificial' enhancement of performances is thence no longer a misdemeanour but, quite the opposite, necessary.

\section{Conclusion}

Although the manner in which the technologisation of bodies is handled may seem very different in both of the cases studied here, their comparison allowed us to highlight some surprising similarities concerning the treatment of the enhanced individual's figure and the concern for sporting fairness.

Whether for the management of the Pistorius case by the sporting institution or for the organisation of the Cybathlon, the actors engaged in each situation seek to establish a certain distance from the imaginary associated to the enhanced individual, all the while participating, paradoxically, to the production of the transhuman athlete figure. On the one hand, in the Olympic and Paralympic context, the question of enhancement is held at a distance by the institution thanks to a strict control over the natural aspect of the performance (Jones and Wilson 2009). On the other hand, with the Cybathlon, the possibility of human enhancement is denied using arguments highlighting the incipient nature of the technology employed. The latter is above all considered as a form of assistance, 'impairment compensation' rather than 'enhancing capacities'. However, although both of these organisations reject the presence of any possible enhancement, both of them participate, more or less directly, in the production of a transhuman figure (Richard and Andrieu 2019). Pistorius' liminal situation, stemming from the many medical tests which made him waver between Olympics and Paralympics, promoted the strengthening of a sports cyborg imagination (Smith 2015) surrounding his performances. For its part, and in an ostensible manner, the Cybathlon showcases the visual codes of the cyborg figure (Wolbring 2018) in order to ensure the promotion of the event. Thus, promoters of Cybathlon are aligned with widely appreciated notions of dystopian societies in which human corporeality is rendered an out-dated concept.

Simultaneously, the sporting world and the Cybathlon organisers both deploy management strategies for the technologised performance of athletes in order to maintain 
sporting fairness. Faced with Pistorius and his claim to participate in the 'non-disabled' sporting world, the federal institution strived to think along the lines of a strict compensation which would not distort the ideal of comparison. The imperative for fairness thus strengthens the abled/disabled dichotomy and the legitimacy of the Olympic/Paralympic duality. The Cybathlon, which uses technology in a positive manner within a competitive setting, ensures equity by shifting the questioning to another focus point: the aim is no longer to measure a performance which is 'exclusively physical', but rather the advantage that an 'impaired' body could gain from an advanced assistive technology.

The comparison between these two cases emphasized the relative and tenuous nature of sporting fairness. In an attempt to become operational, this ideal of equity involves categories which are necessarily fragile and difficult to justify when they are faced with reality. The justification for equity is finally situated in a causa sui structure: the natural/ artificial and disability/ability/enhancement categories are employed in order to justify a sporting equity which, in turn, becomes itself an element of justification for (re)producing these categories. The comparison of these two cases also questions the position of the performance of disabled athletes using advanced assistive technologies in the sporting panorama. The way in which fairness is managed is indicative of this position. By ensuring that Pistorius does not gain too much advantage from the use of his prostheses, the IOC seeks to maintain the traditional vision of Olympic fairness. Cybathlon, which values the advantage that a person can derive from technology, challenges this vision of fairness. Despite the organisers' desire to make the Cybathlon part of the (Para)Olympic tradition, the way they assess technologized performance and ensure fairness seems to bring it closer to the culture of motor sports, or other emerging practices such as drone racing (Tham 2020) or Esports (Hemphill 2005).

\section{Notes}

1. The term cyborg is a contraction of the word 'cybernetic' and the word 'organism' (Wiener 1961).

2. Born with fibula hemimelia, he was amputated of both legs and started using prosthetics at a very young age.

3. George Eyser (gymnastics in the 1904 Olympics). Even after the institutionalisation of a specific competition for athletes designated as disabled; we can cite the cases of Neroli Fairhall (archery in the 1984 Olympics) and Marla Runyan (women's 1500-metre race in the 2000 Olympics).

4. He broke the world record (T43 class) less than one month after beginning athletics. At the 2008 Paralympic Games, he won 3 gold medals.

5. Neither the regulation of athlete bodies that are not easily categorized, nor the medicalization approach used by the IAAF, are specific to Pistorius. In another paper Issanchou, Ferez, de Léséleuc (2018), we worked on similarities between Oscar Pistorius and Caster Semenya's cases.

6. This rule bans the use of technical devices procuring an advantage on those athletes who do not use them.

7. IAAF secretary-general Pierre Weiss said Pistorius will be contacted with the news that there is no ban and he will not be excluded without scientific evidence against him.

8. For the sporting significance of this procedure, (see Issanchou, Ferez, and de Léséleuc 2018; Issanchou, Léséleuc, and Boisvert 2017; Léséleuc and Issanchou 2016). 
9. For more details concerning the indicators used by Professor Brüggemann, see the CAS report.

Available at http://jurisprudence.tas-cas.org/Shared\%20Documents/1480.pdf

10. Court of Arbitration for Sport, page 14.

Available at http://jurisprudence.tas-cas.org/Shared\%20Documents/1480.pdf

11. He was eliminated in the semi-finals in 2011 and in 2012.

12. The iconographic representations of Oscar Pistorius, largely relayed by the media, are strongly revealing of this fiction of technological human surpassing.

13. http://www.atlantico.fr/decryptage/jo-nouveau-genre-auront-lieu-en-suisse-en-octobreet-athletes-seront-cyborgs-cybathlon-premiers-jeux-olympiques-bioniques- 2643780 . htmlhttp://thenextweb.com/insider/2016/03/29/worlds-first-cyborg-olympics-coming/ \#grefhttp://www.arte.tv/magazine/futuremag/fr/cybathlon-des-jo-pour-cyborg-futuremag

14. It is interesting to note the implication of the ETH Zurich in research programs concerning robot-assisted sport training: http://www.sms.hest.ethz.ch/research/current-researchprojects/robot-assisted-training-in-sports.html

15. ETH community magazine September, p. 5:https://www.ethz.ch/content/dam/ethz/associ ates/services/News/life/ausgaben/englisch/eth_life_16_3_EN.pdf

16. http://www.cybathlon.ethz.ch/cybathlon-news/2016/09/congratulations-to-our-experts.html

17. https://www.paralympic.org/the-ipc/about-us

18. https://www.ethz.ch/en/news-and-events/eth-news/news/2015/05/interview_robert_riener. $\mathrm{html}$

\section{Disclosure Statement}

No potential conflict of interest was reported by the author(s).

\section{ORCID}

Rémi Richard (D) http://orcid.org/0000-0002-6170-367X

\section{References}

ADAM, C.E. and P. TRABAL. 2013. Les performances controversées d'Oscar Pistorius en athlétisme. In Sport et controverses, edited by C. Collinet and P. Terral. Paris: Éditions des archives contemporaines: 19-39.

BENSA, A. and E. FASSIN. 2002. Les sciences sociales face à l'événement. Terrain 38: 5-20. doi:10.4000/ terrain.1888.

Bourdieu, p. 1994. Les Jeux olympiques. Actes de la recherche en sciences sociales 103: 102-03. doi:10.3406/arss.1994.3104.

BRown, A. 2015. Principles of stakes fairness in sport. Politics, Philosophy \& Economics 14 (2): 152-86. doi:10.1177/1470594X14523525.

CARR, C.L. 2008. Fairness and performance enhancement in sport. Journal of the Philosophy of Sport 35 (2): 193-207. doi:10.1080/00948705.2008.9714738.

CARSTAIRS, c. 2003. The wide world of doping: Drug scandals, natural bodies, and the business of sports entertainment. Addiction Research \& Theory 11 (4): 263-81. doi:10.1080/1606635031000135659.

CLÉRET, L. and M. MCNAMEE. 2012. Olympism, the values of sport, and the will to power: De Coubertin and Nietzsche meet Eugenio Monti. Sport, Ethics and Philosophy 6 (2): 183-94. doi:10.1080/ 17511321.2012.668142.

CORRIGAN, T.F., J. PATON, E. HOLT, and M. HARDIN. 2010. Discourses of the "Too Abled": Contested body hierarchies and the Oscar Pistorius case. International Journal of Sport Communication 3: 288-307. doi:10.1123/ijsc.3.3.288.

СуватнцоN. 2016. Cybathlon races \& rules. V_2016.08.10. Zurich: ETH. 
DELEUZE, G. 1969. Logique du sens. Paris: Les Éditions de Minuit.

DYER, в. 2020. A pragmatic approach to resolving technological unfairness: The case of Nike's Vaporfly and Alphafly running footwear. Sports Medicine - Open 6 (1): 21. doi:10.1186/s40798-020-00250-1.

FRIAS, F.J.L. 2016. The defining components of the Cyborg: Cyborg-athletes, fictional or real? Sport, Ethics and Philosophy 10: 97-111. doi:10.1080/17511321.2016.1171249.

gaRdou, c. 1997. Les personnes handicapées exilées sur le seuil. Revue Européenne du Handicap Mental 14: 6-17.

GLEAVES, J. and T. LEHRBACH. 2016. Beyond fairness: The ethics of inclusion for transgender and intersex athletes. Journal of the Philosophy of Sport 43 (2): 311-26. doi:10.1080/00948705.2016.1157485. HEMPHILL, D. 2005. Cybersport. Journal of the Philosophy of Sport 32 (2): 195-207. doi:10.1080/ 00948705.2005 .9714682 .

HOWE, p.D. 2011. Cyborg and supercrip: The paralympics technology and the (Dis)empowerment of disabled athletes. Sociology 45: 868-82. doi:10.1177/0038038511413421.

ISSANCHOU, D., É. LÉSÉLEUC, and Y. BOISVERT. 2017. La performance "trop" importante d'Oscar Pistorius: Les limites de la (dé)mesure sportive. Actes du $2^{e}$ Congrès International de l'Association Française $d^{\prime}$ Ethnologie et d'Anthropologie, Toulouse, 87-97.

ISSANCHOU, D.S., FEREz, and E. DE LÉSÉLEUC. 2018. Technology at the service of natural performance: Cross analysis of the Oscar Pistorius and Caster Semenya cases. Sport in Society 21: 689-704. doi:10.1080/17430437.2016.1273633.

JONES, C. and C. WILSON. 2009. Defining advantage and athletic performance: The case of Oscar Pistorius. European Journal of Sport Science 9: 125-31. doi:10.1080/17461390802635483.

JONES, C. and P.D. HOWE. 2005. The conceptual boundaries of sport for the disabled: Classification and athletic performance. Journal of the Philosophy of Sport 32: 133-46. doi:10.1080/00948705.2005.9714678.

LÉSÉLEUC, E. and D. ISSANCHOU. 2016. Sport and disability: Pistorius does not fit with the categories.

International Review of Sociology 26: 513-28. doi:10.1080/03906701.2016.1223587.

LOLAND, s. 2018. Performance-enhancing drugs, sport, and the ideal of natural athletic performance. The American Journal of Bioethics 18 (6): 8-15. doi:10.1080/15265161.2018.1459934.

LOLAND, S. and H. HOPPELER. 2012. Justifying anti-doping: The fair opportunity principle and the biology of performance enhancement. European Journal of Sport Science 12 (4): 347-53. doi:10.1080/ 17461391.2011.566374.

MAGDALINSKI, T. 2012. Enhancing the body from without: Artificial skins and other prosthetics. Routledge Online Studies on the Olympic and Paralympic Games 1 (37): 109-27. doi:10.4324/ 9780203099384_chapter_7.

marcelini, A., S. Ferez, D. ISSANChOU, E. DE léséleuc, and M. mCNAMEe. 2012. Challenging human and sporting boundaries: The case of Oscar Pistorius. Performance Enhancement \& Health 1: 3-9. doi:10.1016/j. peh.2011.11.002.

MARCHETTI, D. 2002. Les transformations de la production de l'information sportive: Le cas du sportspectacle. Les cahiers du journalisme 11: 66-81.

MarTínKovÁ, 1. 2012. Fair or temple: Two possibilities for Olympic sport. Sport, Ethics and Philosophy 6: 166-82. doi:10.1080/17511321.2012.669396.

MCNAMEE, M. and J. PARRY. 2014. Olympic ethics and philosophy. London: Routledge.

MIAH, A. 2003. Be very afraid: Cyborg athletes, transhuman ideals \& posthumanity. Journal of Evolution

\& Technology 13 (2). Available at https://www.jetpress.org/volume13/miah.html.

NORMAN, M.E. and F. MOOLA. 2011. "Bladerunner or boundary runner"?: Oscar Pistorius, Cyborg transgressions

and strategies of containment. Sport in Society 14: 1265-79. doi:10.1080/17430437.2011.614783.

PAPA, F. 1998. Du signal universel à la pluralité des images. Communications 67: 91-103. doi:10.3406/

comm.1998.2018.

PARRY, J. 2019. E-sports are not sports. Sport, Ethics and Philosophy 13 (1): 3-18. doi:10.1080/

17511321.2018.1489419.

PICKERING FRANCIS, L. 2005. Competitive sports, disability, and problems of justice in sports. Journal of the

Philosophy of Sport 32: 127-32. doi:10.1080/00948705.2005.9714677.

REID, H. 2017. Athletes as heroes and role models: An ancient model. Sport, Ethics and Philosophy 11: 40-

51. doi:10.1080/17511321.2016.1261931. 
RICHARD, R. and B. ANDRIEU. 2019. The Cybathlon experience: Beyond transhumanism to capability hybridization. Journal of the Philosophy of Sport 46 (1): 49-62. doi:10.1080/00948705.2018.1561297. RIENER, R. 2016. The Cybathlon Promotes the development of assistive technology for people with physical disabilities. Journal of Neuroengineering and Rehabilitation 13. Available at https://www. ncbi.nlm.nih.gov/pmc/articles/PMC4886429/.

RYALL, E. 2013. Conceptual problems with perfomance enhancing technology in sport. Royal Institute of Philosophy Supplement 73: 129-143.

SASHKIN, M. and R.L. WILLIAMS. 1990. Does fairness make a difference? Organizational Dynamics 19 (2): $56-$ 71. doi:10.1016/0090-2616(90)90071-V.

SMITH, L.R. 2015. The blade runner: The discourses surrounding Oscar Pistorius in the 2012 Olympics and Paralympics. Communication \& Sport 3: 390-410. doi:10.1177/2167479513519979.

SPARKES, A.C., J. BRIGHTON, and K. INCKLE. 2018. 'It's a part of me': An ethnographic exploration of becoming a disabled sporting cyborg following spinal cord injury. Qualitative Research in Sport, Exercise and Health 10 (2): 151-66. doi:10.1080/2159676X.2017.1389768.

SWARTZ, L. and B. WATERMAYER. 2008. Cyborg anxiety: Oscar Pistorius and the boundaries of what it means to be human. Disability \& Society 23 (2): 187-90. doi:10.1080/09687590701841232.

TEETZEL, s. 2006. On transgendered athletes, fairness and doping: An international challenge. Sport in Society 9 (2): 227-51. doi:10.1080/17430430500491280.

THAM, A. 2020. Negotiating leisure etiquette in the context of drones. Leisure/Loisir 44 (1): 105-26. doi:10.1080/14927713.2020.1745674.

TURNER, v·w. 1990. Le phénomène rituel. Structure et contre-structure. Paris: PUF.

VAN HILVOORDE, I. and L. LANDEWEERD. 2008. Disability or extraordinary talent-Francesco Lentini (Three legs) versus Oscar Pistorius (No legs). Sport, Ethics and Philosophy 2 (2): 97-111. doi:10.1080/ 17511320802221778.

VAN HILVOORDE,. and $\mathrm{N}$. Рот. 2016. Embodiment and fundamental motor skills in eSports. Sport, Ethics and Philosophy 10 (1): 14-27. doi:10.1080/17511321.2016.1159246.

WIENER, N. 1961. Cybernetics, or control and communication in the animal and the machine. $2^{\text {nd }}$ ed. John Wiley \& Sons Inc: xvii, 212. Cambridge: The M.I.T Press.

WOLBRING, G. 2008. Oscar Pistorius and the future nature of Olympic, Paralympic and other sports.

SCRIPT-Ed 5 (1): 139-60. doi:10.2966/scrip.050108.139.

WOLBRING, G. 2012. Paralympians outperforming Olympians: An increasing challenge for Olympism and the Paralympic and Olympic movement. Sport, Ethics and Philosophy 6 (2): 251-66. doi:10.1080/17511321.2012.667828.

Wolbring, G. 2018. Prostheses and other equipment: The issue of the Cyborg Athlete-Interrogating the media coverage of the Cybathlon 2016 event. In The Palgrave handbook of Paralympic studies, edited by I. Brittain and A. Beacom. London: Palgrave Macmillan: 439-59. 